\title{
Fenotipo clínico mixto de deleción y duplicación de la región del síndrome de Sotos: microdeleción 5q35.2-q35.3 detectada por microarreglo de hibridación genómica comparativa
}

\author{
Héctor A. Loeza-Sierra ${ }^{1 *}$, Héctor A. López-Santos ${ }^{2,3}$ y Dulce M. Castro-Coyot ${ }^{2}$ \\ ${ }^{1}$ Facultad de Medicina, Benemérita Universidad Autónoma de Puebla; ${ }^{2}$ Centro de Rehabilitación e Inclusión Infantil Teletón Puebla; ${ }^{3}$ Universidad \\ de la Salud del Estado de Puebla. Puebla, Puebla, México
}

\begin{abstract}
Resumen
Introducción: El síndrome de Sotos es una enfermedad hereditaria caracterizada por el sobrecrecimiento prenatal y posnatal, con edad ósea avanzada, facies característica y retraso del desarrollo. Caso clínico: Se reporta el caso de un paciente con síndrome de Sotos y manifestaciones clínicas no descritas previamente, diagnosticado por microarreglos de hibridación genómica comparativa. Se detectó la duplicación de un gen y la deleción de 43 genes, entre los que se encuentran NSD1, gen asociado al síndrome de Sotos. La pérdida y la ganancia de estos otros genes pueden explicar las características atípicas en este paciente. Conclusiones: Por las características atípicas, el microarreglo de hibridación genómica comparativa fue una herramienta útil para el diagnóstico. Las alteraciones cromosómicas encontradas en este paciente demuestran la heterogeneidad clínica de las enfermedades genómicas.
\end{abstract}

Palabras clave: Síndrome de Sotos. Hibridación genómica comparativa. Gen NSD1.

\section{Mixed clinical phenotype of deletion and duplication of the Sotos syndrome region: 5q35.2-q35.3 microdeletion detected by CGH array}

\begin{abstract}
Background: Sotos syndrome is an inherited disease characterized by pre- and postnatal overgrowth with advanced bone age, characteristic facies, and developmental delay. Case report: We report the case of a patient with Sotos syndrome and clinical manifestations not described previously, who was diagnosed comparative genomic hybridization arrangements (CGH array). The duplication of a gene and the deletion of 43 genes were identified, among which is the NSD1 gene, associated with Sotos syndrome. The gain and loss of these other genes may explain the atypical characteristics present in the patient. Conclusions: Due to its atypical characteristics, the CGH array was a useful tool for diagnosis. The chromosomal alterations found in this patient demonstrate the clinical heterogeneity of genomic diseases.
\end{abstract}

Keywords: Sotos syndrome. Comparative genomic hybridization. NSD1 gene.

Correspondencia:

*Héctor A. Loeza-Sierra

E-mail: andreslsierra.hals@gmail.com
Available online: $27-07-2021$ Bol Med Hosp Infant Mex. 2021;78(5):489-494

www.bmhim.com 1665-1146/@ 2021 Hospital Infantil de México Federico Gómez. Published by Permanyer. This is an open access article under the CC BY-NC-ND license (http://creativecommons.org/licenses/by-nc-nd/4.0/). 


\section{Introducción}

El síndrome de Sotos (OMIM \#117550) es una enfermedad hereditaria poco frecuente, con una prevalencia de $1: 15,000^{1}$. Se caracteriza por un sobrecrecimiento prenatal y posnatal, con edad ósea avanzada, facies características y retraso del desarrollo ${ }^{2}$, además de macrodolicocefalia, protuberancia frontal, escasez de cabello frontoparietal, aparente hipertelorismo y fisuras palpebrales descendentes. También se describen problemas de comportamiento, anomalías congénitas cardiacas, ictericia neonatal, anomalías renales, escoliosis y convulsiones. Debido a que las dificultades psicomotoras son más aparentes durante la infancia, el síndrome de sobrecrecimiento puede pasar desapercibido en edades más avanzadas. Es importante señalar que la apariencia facial característica o gestalt (cara redonda, frente prominente y abombada, hipertelorismo aparente, fisuras palpebrales descendentes, paladar ojival, puente nasal plano, sensación de calvicie frontoparietal, barbilla puntiaguda y pabellones auriculares grandes) es uno de los criterios diagnósticos más específicos del síndrome ${ }^{3,4}$. Este síndrome está causado por haploinsuficiencia del gen NSD1 (localizado en $5 \mathrm{q} 35$ ), secundaria a mutaciones puntuales 0 deleciones en el $90 \%$ de los casos ${ }^{1}$. En pocos casos reportados se han descrito microdeleciones del locus $5 q 35$, en el que está ubicado el gen.

Este gen codifica para una histona metiltransferasa implicada en la regulación transcripcional. La delimitación del síndrome y el diagnóstico se basan en las características clínicas y la historia evolutiva, y se confirman con pruebas moleculares que evidencien mutaciones capaces de afectar el funcionamiento del gen $N S D 1^{5}$. Las técnicas más utilizadas para el diagnóstico son la hibridación in situ fluorescente (FISH, fluorescent in situ hybridization) y la ampliación de sondas múltiples dependientes de ligación (MLPA, multiplex ligation-dependent probe amplification). Los estudios de arreglo de hibridación genómica comparativa (CGH, comparative genomic hybridization) permiten una caracterización de las anomalías más precisa que la FISH y la MLPA, ya que permiten el diagnóstico de síndromes de microdeleción (involucro de varios genes) con puntos de rotura atípicos que pueden ser no detectables por estas dos técnicas.

El arreglo de hibridación genómica comparativa permite explorar simultáneamente la dosis de ADN en múltiples loci del genoma, al comparar las cantidades relativas de ADN de dos genomas (control y paciente) marcados con fluorocromos distintos, que se unen con fragmentos de ADN de secuencia conocida 0 "sondas» fijadas a un portaobjetos o soporte de vidrio. El color de la fluorescencia en cada punto del arreglo informa sobre la cantidad relativa de cada ADN y permite inferir la presencia de ganancias o pérdidas en regiones concretas del genoma ${ }^{6}$.

\section{Caso clínico}

Varón de 4 años en el momento de la evaluación clínica. Se reportaron los siguientes antecedentes de importancia: producto de gesta 2, con padres de 35 y 40 años en el momento del embarazo, previamente sanos, no consanguíneos; hermano de 5 años, sin comorbilidad ni malformaciones. Durante el embarazo, la madre cursó con adecuado control prenatal; presentó infección de vías urinarias en el sexto mes de embarazo. El paciente se obtuvo a las 34 semanas de gestación por parto eutócico, con peso de $2550 \mathrm{~g}$, talla de $50 \mathrm{~cm}$ y Apgar 7/9. Fue hospitalizado durante 17 días por dificultad respiratoria, hiperbilirrubinemia, hemorragia subependimaria izquierda, plexos coroides engrosados, foramen oval de $2.5 \mathrm{~mm}$, conducto arterioso permeable e hipertensión pulmonar. A los 2 días de vida se detectó sepsis neonatal, con datos de hipotonía generalizada y succión débil. A las 3 semanas de vida presentó datos de neumonía por broncoaspiración (por mal manejo de la succión y la deglución), misma que se repitió a los 4 meses de vida. Se detectaron datos de escoliosis a los 6 meses, por lo que se inició tratamiento. A los 3 años y 5 meses de edad, el servicio de reumatología pediátrica y hematología le diagnosticó síndrome antifosfolípido (detectado por datos de anemia hemolítica, trombocitopenia y presencia de anticuerpos anticardiolipina y anticoagulante lúpico). Por asociación se descartó la presencia de lupus eritematoso sistémico. Actualmente, el paciente se encuentra en tratamiento con ácido acetilsalicílico y glucocorticoides.

Con retraso en el desarrollo psicomotor, inicio de la dentición a los 7 meses, sostén cefálico al octavo mes, sedestación e inicio de monosílabos a los 15 meses, bipedestación a los 3 años y marcha a los 3 años y 8 meses, el paciente acude a valoración por escoliosis y retraso global del neurodesarrollo.

En la exploración física se detecta peso de $14,200 \mathrm{~g}$ (percentil 3-10), talla de $97.5 \mathrm{~cm}$ (percentil 10-25) y perímetro cefálico de $53.5 \mathrm{~cm}$ (> percentil 97). Así mismo, se observa macrocefalia, cara triangular, frontal amplio, cabello de implantación alta, puente nasal deprimido, nariz corta, filtrum largo, micrognatia, cuello 
sin alteraciones, tórax en quilla con asimetría por elevación del hemitórax izquierdo, exploración cardiopulmonar sin compromiso, columna con escoliosis dorsal izquierda grave, abdomen sin megalias, genitales fenotípicamente masculinos, y miembros torácicos y pélvicos simétricos, íntegros e hipotróficos.

Se realizó una comparación entre las características de este paciente y aquellas más comunes en el síndrome de Sotos (Tabla 1).

Los resultados de los estudios paraclínicos fueron los siguientes: radiografía de columna con escoliosis dorsolumbar de convexidad izquierda y vértebra transicional lumbosacra; electroencefalograma anormal por lentificación, desorganización en forma genera lizada; tomografía de cráneo con datos de inmadurez cerebral; ecocardiograma con conducto arterioso permeable e hipertensión pulmonar moderada (actualmente ya con cierre por cateterismo); serie esofagogastroduodenal con moderado reflujo gastroesofágico; ultrasonido abdominal que muestra riñones con ligera dilatación de las pelvicillas; hígado con quiste simple de $11 \times 6 \times$ $12 \mathrm{~mm}$ y volumen de $0.4 \mathrm{~mm}^{3}$, y tiempo de tromboplastina parcial de 348.6 segundos. A los 13 meses de edad cronológica, la edad ósea fue de 3 meses, y a los 20 meses, de 12 meses.

Se realizó cariotipo en linfocitos de sangre periférica mediante la técnica convencional y microarreglo de hibridación genómica comparativa. El cariotipo se reportó normal 46, XY [30 metafases revisadas]. Por otro lado, el microarreglo de hibridación genómica comparativa detectó las variaciones que se resumen en la tabla 2. La fórmula cromosómica según la nomenclatura ISCN 2013 es la siguiente:

arr3q26.1(165, 187,477-165,822,834)x3,5q35. 2-q35.3(175,571,962-177,422,761)x1.

Se detectó una duplicación de $0.635 \mathrm{Mb}$ en la región cromosómica 3q26.1 (Figura 1). Esta duplicación no se ha encontrado descrita en la bibliografía ni en las bases de datos consultadas. El único gen involucrado en la duplicación es $B C h E$, el cual está asociado con deficiencia de butirilcolinesterasa (OMIM \#177400), que sigue un patrón de herencia autosómica recesiva. El fenotipo al que se asocia no coincide con el que muestra el paciente, por lo que es probable que esta duplicación no se asocie con la clínica que presenta.

La deleción contiene 43 genes, entre los que se encuentra NSD1, lo que se considera con significado clínico ya que coincide con la región asociada comúnmente al síndrome de Sotos (Figura 2). Los 42 genes
Tabla 1. Características clínicas del paciente con síndrome de Sotos

\begin{tabular}{|c|c|}
\hline Características del síndrome de Sotos & Paciente \\
\hline $\begin{array}{l}\text { Alteraciones estructurales del sistema nervioso } \\
\text { central }\end{array}$ & Presente \\
\hline Anomalías de la alimentación y reflujo & Presente \\
\hline Anomalías tiroideas & Presente \\
\hline Cardiopatías & Presente \\
\hline Coloración rosada de las mejillas y la nariz & Presente \\
\hline Dificultades para el aprendizaje & Presente \\
\hline Dolicocefalia & Presente \\
\hline Electroencefalograma anormal & Presente \\
\hline Escoliosis & Presente \\
\hline Fisuras palpebrales hacia abajo & Presente \\
\hline $\begin{array}{l}\text { Frente prominente con línea de implantación del } \\
\text { cabello alta }\end{array}$ & Presente \\
\hline Habilidades motoras finas retrasadas & Presente \\
\hline Hiperbilirrubinemia al nacimiento & Presente \\
\hline Hipotonía & Presente \\
\hline Infecciones respiratorias frecuentes & Presente \\
\hline Macrocefalia & Presente \\
\hline Mentón prominente y puntiagudo & Presente \\
\hline Paladar alto & Presente \\
\hline Retraso en el desarrollo & Presente \\
\hline Retraso en el lenguaje & Presente \\
\hline Constipación o megacolon & Ausente \\
\hline Convulsiones & Ausente \\
\hline Crecimiento acelerado durante la infancia & Ausente \\
\hline Edad ósea avanzada (> p97) & Ausente \\
\hline Erupción prematura de dientes & Ausente \\
\hline Estrabismo y nistagmo & Ausente \\
\hline Hemihipertrofia & Ausente \\
\hline Intolerancia a la glucosa & Ausente \\
\hline Luxaciones de caderas, pie equino varo & Ausente \\
\hline Manos y pies exageradamente grandes & Ausente \\
\hline Peso y talla incrementados al nacimiento & Ausente \\
\hline Trastornos de la conducta & Ausente \\
\hline Tumores & Ausente \\
\hline
\end{tabular}

restantes no se han asociado a ningún síndrome específico. 


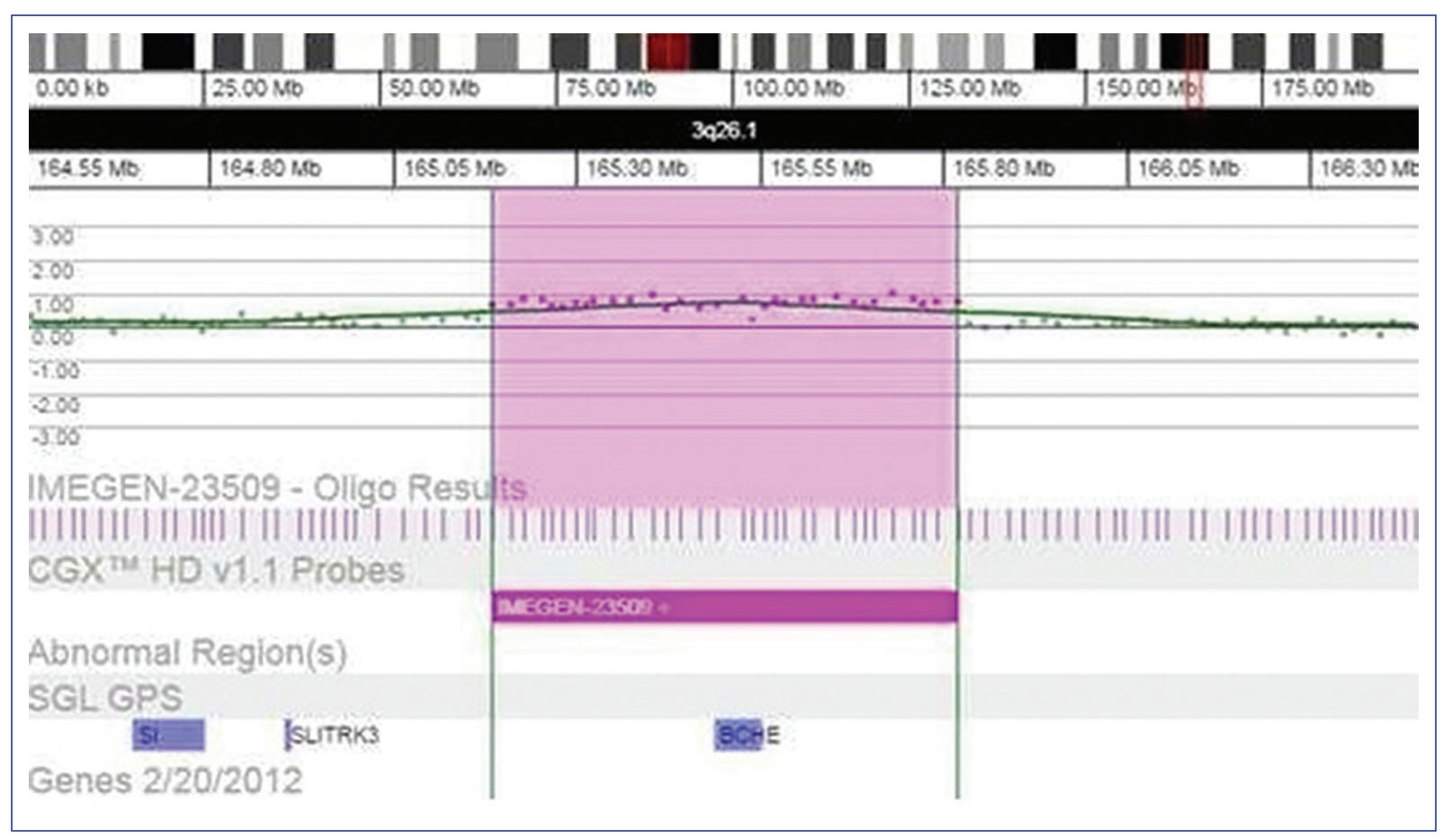

Figura 1. Imagen representativa de la región $3 q 26.1$, una duplicación de $0.635 \mathrm{Mb}$ que involucra al gen $B C h E$, no relacionado con el fenotipo del paciente. (Fuente: reporte de resultados del laboratorio de referencia, Genos Médica Centro Especializado en Genética, realizado con el software Genoglyphix).

Tabla 2. Variaciones detectadas en el arreglo de hibridación genómica comparativa

\begin{tabular}{|l|c|c|l|}
\hline Cambio & Localización & $\begin{array}{c}\text { Tamaño } \\
(\mathbf{M b})\end{array}$ & Genes contenidos \\
\hline Duplicación & $3 q 26.1$ & 0.635 & Butirilcolinesterasa \\
\hline Deleción & $5 q 35.2-q 35.3$ & 1.851 & 43 genes \\
\hline
\end{tabular}

\section{Discusión}

El síndrome de Sotos es una condición de sobrecrecimiento infantil que fue descrita por primera vez en 1964 por Juan Sotos ${ }^{2}$, aunque el primer paciente puede que se informara en 1931. Los cuatro principales criterios diagnósticos fueron establecidos en 1994 por Cole y Hughes, basándose en la evaluación sistemática de 41 casos típicos: sobrecrecimiento con edad ósea avanzada, macrocefalia, apariencia facial característica y dificultades de aprendizaje $e^{2,4}$.

Aunque este síndrome tiene un patrón de herencia autosómica dominante, el $95 \%$ de los casos se deben a mutaciones genéticas de novo 1 .

Los rearreglos cromosómicos pueden producir desequilibrios, ya sea pérdidas o ganancias de información genética, que pueden ocasionar algún fenotipo específico ${ }^{7}$. De acuerdo con lo descrito, el fenotipo de las ganancias o duplicaciones es menos grave que el de un paciente que presenta deleciones ${ }^{8}$. La duplicación de la región 5q34-q35.3 se ha asociado con un fenotipo inverso del síndrome de Sotos por contener el gen NSD1 en triple dosis. El síndrome se caracteriza por talla baja, microcefalia, alteraciones en el aprendizaje, discapacidad intelectual de leve a moderada, problemas de comportamiento, dismorfias faciales, anomalías esqueléticas, craneosinostosis, defectos cardiacos, criptorquidia, hernias inguinales y edad ósea retrasada. El tamaño de la microduplicación es de aproximadamente $2.0 \mathrm{Mb}^{8,9}$.

Se encontró una deleción de $1.851 \mathrm{Mb}$ en la región 5q35.2-q35.3, con un tamaño y una localización similares a los reportados en microduplicaciones en el paciente del presente caso. Presenta un fenotipo mixto, con características de microdeleción, como son macrocefalia, retraso en el lenguaje, habilidades motoras finas retrasadas, escoliosis, hiperbilirrubinemia, anomalías en la deglución al nacimiento, datos de reflujo gastroesofágico y electroencefalograma anormal, y con características de duplicación, como retraso en la edad ósea, retraso en el desarrollo y cardiopatía. Así mismo, el paciente cuenta con algunas otras características no encontradas en ninguno de los dos 


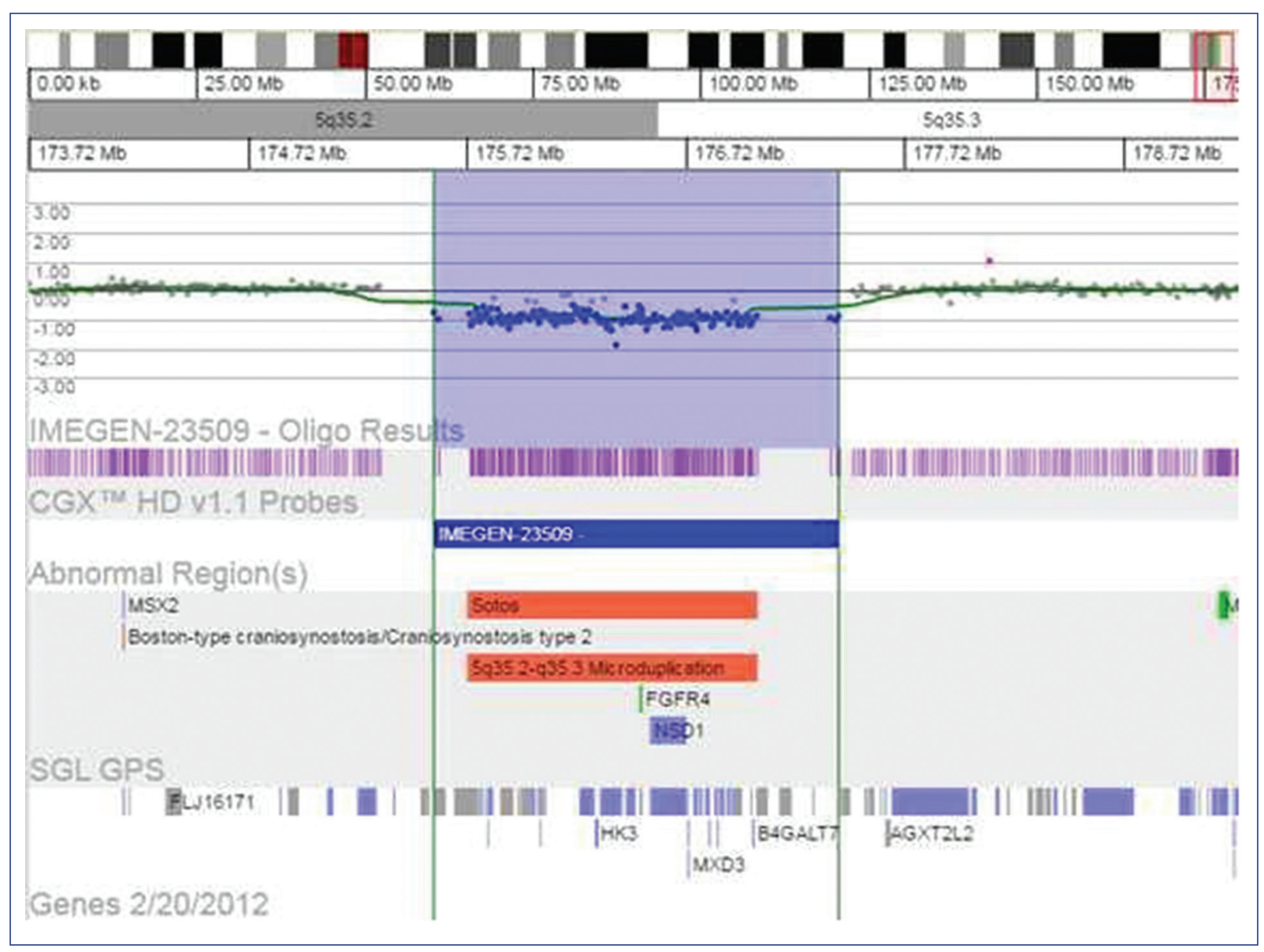

Figura 2. Imagen representativa de la región 5q35.2-q35.3, deleción de 43 genes, entre los que se encuentra NSD1, gen asociado comúnmente con el síndrome de Sotos. (Fuente: reporte de resultados del laboratorio de referencia, Genos Médica Centro Especializado en Genética, realizado con el software Genoglyphix).

síndromes, como peso y talla dentro de los parámetros normales al nacimiento. Lo anterior permite ampliar el espectro fenotípico del síndrome de Sotos, ya que los pacientes pueden presentar un traslape de características al tener una alteración en la región 5q35.2-q35.3, independientemente de que se trate de una pérdida o una ganancia de material genético, lo cual se ha reportado en otros síndromes, pero no en el de Sotos.

No se encontró información en la literatura sobre la relación de este síndrome con el síndrome antifosfolípido. Las mutaciones en el gen F12 (que se encuentra contenido en la región de deleción en este paciente) producen tiempos de coagulación prolongados, lo que puede explicar el tiempo de tromboplastina parcial aumentado.

Los pacientes con síndrome de Sotos tienen un riesgo adicional para el desarrollo de neoplasias, como neuroblastoma, teratoma sacrococcígeo, leucemia linfoblástica aguda y tumor de Wilms, que son los más comúnmente asociados ${ }^{7}$. En el caso presentado, el paciente no cuenta con ningún dato de desarrollo de estos tumores, aunque se mantiene en vigilancia en las consultas de seguimiento.

El microarreglo de hibridación genómica comparativa resulta una herramienta útil para el diagnóstico, y además permite delimitar una correlación genotipo-fenotipo más detallada. Las alteraciones cromosómicas encontradas en este paciente demuestran la heterogeneidad clínica de las enfermedades genómicas.

\section{Responsabilidades éticas}

Protección de personas y animales. Los autores declaran que para esta investigación no se han 
realizado experimentos en seres humanos ni en animales.

Confidencialidad de los datos. Los autores declaran que han seguido los protocolos de su centro de trabajo sobre la publicación de datos de pacientes.

Derecho a la privacidad y consentimiento informado. Los autores han obtenido el consentimiento informado de los pacientes o individuos referidos en el artículo. Este documento obra en poder del autor de correspondencia.

\section{Conflicto de intereses}

Los autores declaran no tener ningún conflicto de intereses.

\section{Financiamiento}

Ninguno.

\section{Bibliografía}

1. Cortès-Saladelafont $E$, Arias-Sáez $K$, Esteban-Oliva D, Coroleu-Lletget W, Martín-Jiménez P, Pintos-Morell G. Síndrome de Sotos: nueva mutación "sin sentido" del gen NSD1 que presenta cutis laxa neonatal. An Pediatr (Barc). 2011;75:129-33.

2. Kılıç $E$, Utine GE, Boduroğlu K. A case of Sotos syndrome with $5 q 35$ microdeletion and novel clinical findings. Turk J Pediatr. 2013;55:207-9.

3. Lapunzina P. Síndrome de Sotos. Protoc Diagn Ter Pediatr. 2010;1:71-9.

4. Saldarriaga W, Molina-Barrera LC, Ramírez-Cheyne J. Síndrome de Sotos por hibridación genómica comparativa. Rev Chil Pediatr. 2016;87:288-92.

5. Moretti-Ferreira D, Koiffmann CP, Wajntal A, Diament AJ, De Mendonça BB, Mattieli J, et al. [Macrosomia, macrocrania and motor disorders in childhood, Sotos syndrome (McKusick 11755): report of 7 cases and review of clinical aspects of 198 reported cases]. Arq Neuropsiquiatr. 1991;49:164-71.

6. Castells-Sarret N, Cueto-González AM, Borregan M, López-Grondona F Miró R, Tizzano E, et al. Array CGH como primera opción en el diagnóstico genético: 1000 casos de análisis de coste y beneficio. An Pediatr (Barc). 2018:89:3-11.

7. Baujat G, Cormier-Daire V. Sotos syndrome. Orphanet J Rare Dis. 2007;2:36.

8. Vázquez-del Campo AR, Torres-Maldonado L, Sánchez-Sandoval S, Frías-Vázquez S, Lieberman-Hernández E, del-Castillo-Ruiz V, et al. Duplicación 5q34q35.3 que involucra el gen NSD1: región delimitada por microarreglos de hibridación genómica comparativa. A propósito de un caso. Acta Pediatr Mex. 2016;37:271-81.

9. Zhang H, Lu X, Beasley J, Mulvihill JJ, Liu R, Li S, et al. Reversed clinical phenotype due to a microduplication of Sotos syndrome region detected by array CGH: microcephaly developmental delay and delayed bone age. Am J Med Genet Part A. 2011;155:1374-8. 